\title{
Vitamin K effects in human health: new insights beyond bone and cardiovascular health
}

\author{
Mario Fusaro $^{1,2} \cdot$ Maurizio Gallieni ${ }^{3} \cdot$ Camillo Porta $^{4,5} \cdot$ Thomas L. Nickolas $^{6} \cdot$ Pascale Khairallah $^{6}$
}

Received: 17 October 2019 / Accepted: 2 December 2019

(C) Italian Society of Nephrology 2019

\begin{abstract}
Vitamin $\mathrm{K}$ is a cofactor for the function of the enzyme $\gamma$-glutamyl carboxylase, necessary for the activation of multiple vitamin K dependent-proteins. Vitamin K dependent-proteins (VKDPs) have important roles in bone health, vascular health, metabolism, reproduction as well as in cancer progression. Vitamin K deficiency is common in different conditions, including kidney disease, and it may influence the activity of VKDPs. This review discusses vitamin K status in human health and the physiologic and pathologic roles of VKDPs, beyond the established effects in skeletal and cardiovascular health.
\end{abstract}

Keywords Vitamin K · Bone disease · Vascular calcifications · Cancer · Chronic kidney disease

\section{Introduction}

The vitamin $\mathrm{K}$ family is comprised of a group of fat-soluble molecules that share the 2-methyl-1,4-naphthoquinone (3-) groups. Vitamin K exists in 3 main forms, K1 and K2 which are the natural form, and $\mathrm{K} 3$ or menadione which is the synthetic form of the vitamin [1]. Vitamin K1, also known as phylloquinone, is found in vegetables, while vitamin K2, also known as menaquinone, is found in fermented food or

Thomas L. Nickolas and Pascale Khairallah contributed equally to this work.

Mario Fusaro

dante.lucia11@gmail.com

1 National Research Council (CNR), Institute of Clinical Physiology (IFC), Pisa Via G. Moruzzi 1, 56124 Pisa, PI, Italy

2 Department of Medicine, University of Padova, Via Giustiniani 2, 35128 Padua, PD, Italy

3 Nephrology and Dialysis Unit, ASST Fatebenefratelli Sacco, Department of Clinical and Biomedical Sciences 'Luigi Sacco', Università di Milano, Milan, Italy

4 Department of Internal Medicine and Therapeutics, University of Pavia, Pavia, Italy

5 Division of Translational Oncology, IRCCS "Istituti Clinici Scientifici Maugeri”, Pavia, Italy

6 Division of Nephrology, Department of Medicine, Columbia University Medical Center, 622 West 168th Street, PH2-124, New York City, NY 10032, USA produced by the intestinal microbiota. Vitamin $\mathrm{K} 1$ can be converted into vitamin K2. Two mechanisms of action of vitamin $\mathrm{K}$ have been described to date. It is an essential cofactor for the function of the enzyme $\gamma$-glutamyl carboxylase, and it acts as a ligand of the steroid and xenobiotic receptor $(\mathrm{SXR})$ and pregnane $\mathrm{X}$ receptor (PXR, murine ortholog) [2].

Vitamin K-dependent proteins (VKDPs) play important roles in human physiology and can be an important link between the bone and the vasculature. This link becomes particularly important in patients with chronic kidney disease (CKD) who have a high prevalence of both mineral bone disorders (MBD) and vascular calcification (VC) [3] and whose primary cause of death is cardiovascular disease. Osteocalcin (OCN) is a VKDP known to be involved in bone mineralization, while Matrix GLA protein (MGP) is a known VC inhibitor whose deficiency is associated with increased risk for VC in CKD. New VKDPs have been discovered, and they have been found to play important roles in various cancers and their therapies.

While many questions have been answered, many more remain regarding the roles of the VKDPs in bone and vascular physiology. This review will discuss the roles of VKDPs and vitamin $\mathrm{K}$ in different pathologies. 


\section{Vitamin K dependent protein (VKDPs)}

Vitamin $\mathrm{K}$ is an essential cofactor required for the activation of the gamma glutamyl carboxylase which converts glutamic acid to $\gamma$-glutamic acid residues. There are several vitamin $\mathrm{K}$ dependent proteins (VKDPs) [4]. These include the coagulation factors proteins $\mathrm{C}, \mathrm{S}, \mathrm{M}, \mathrm{Z}$, factors VII, IX, X and prothrombin. VKDPs also include Bone Gla Protein (BGP, or osteocalcin), Matrix Gla Protein (MGP), Gas6 (Growth Arrest-Specific 6 Protein), GRP (Gla Rich Protein) and Periostin. VKDPs play established roles in coagulation, in bone health and in cardiovascular health.

\section{Bone Gla protein (BGP): beyond skeletal health}

Bone Gla protein or osteocalcin is the most abundant protein in bone. It is mainly secreted by osteoblasts, with a smaller amount secreted by chondrocytes [5]. BGP undergoes three carboxylation events to be transformed from the undercarboxylated form into the fully functional form. These carboxylation events require vitamin K as a cofactor [6]. Several mechanisms describing the BGPs role in bone physiology have been proposed, including the inhibition of bone mineralization [7], the regulation of the rate of mineral maturation [8], and the formation of a complex between bone matrix and collagen in order to increase bone toughness [9]. However, none of these mechanisms are fully proven.

More recently, the relationship between BGP and glucose metabolism has been elucidated. In this role, BGP is thought to be released into the circulation and to exert an action similar to a hormonal effect [10]. This shed light into the peripheral functions of BGP and led to increased interest in this protein, therefore uncovering a wide range of functions.

The role of BGP in glucose metabolism and insulin signaling was first discovered by Lee et al. [11] whose experiments showed that BGP knockout mice develop glucose intolerance, insulin resistance, and increased adipose tissue. The circulating form of BGP exerting the metabolic effects is mostly the undercarboxylated form (ucBGP). By binding to the receptor Gprc6a, in animals ucBGP acts on the pancreatic beta cells [10]. The influence of BGP on insulin sensitivity may be mediated via its effect on adiponectin, independent of insulin secretion [11]. Human studies have not shown this metabolic effect, however. When Basu et al. administered insulin to seven diabetic and seven non-diabetic patients and assessed the association with bone turnover markers, the change in the insulin levels did not influence BGP and ucBGP levels [12]. In humans, BGP also acts on Leydig cells thereby affecting the reproductive function of males [13].
Beyond the metabolic functions, BGP is involved in vascular calcification (VC) modulation through its effect on adiponectin [11]. Adiponectin inhibits osteoblastic differentiation of vascular smooth muscle cells, therefore protecting against VC [14]. In apolipoprotein E-deficient mice, daily injections of BGP for 12 weeks resulted in endothelium protection from atherosclerosis, but whether this was also mediated by the concomitant improvement in glucose metabolism is unknown [15]. Similarly, diabetic rats given daily injections of BGP had an improvement in arterial stiffness as assessed by pulse wave velocity [16].

The role of BGP in modulating and possibly preventing VC was confirmed in humans. BGP may exert this effect through its interaction with adiponectin, as seen by Bacchetta et al. when they found a significant association between BGP and adiponectin in CKD patients [17].

In human cardiovascular tissues, BGP was found in higher concentrations in calcified aorta and valves as compared to non-calcified tissue [18]. Fusaro et al. found lower BGP levels in patients with aortic and iliac calcifications as compared to patients without calcifications [19]. In men aged 51-85 years old in the MINOS study, higher total BGP levels were associated with slower progression of abdominal aortic calcification after a 10 year follow up [20].

In contrast to the above findings, in the Study of Osteoporotic Fractures (SOF) which enrolled 363 elderly women, total BGP levels were not associated with abdominal aortic calcification [21].

Moreover, in a meta-analysis of 46 clinical studies evaluating the relationship between BGP and $\mathrm{VC}$, no definite associations could be found between the different forms of BGP (ucBGP, cBGP and total BGP) and VC. However, sound physiological conclusions cannot be drawn based on these findings. In fact, $44 \%$ of the included studies did not adjust for confounding variables and the BGP forms were measured using different assays in the different studies [22]. Moreover, BGP displays a circadian rhythm with levels falling in the morning and reaching the peak in the evening [23]. Therefore, the timing of blood draws may impact the results of the studies. It is also important to note that BGP is cleared by the kidneys [24]. Therefore any decline in renal function results in an elevation in BGP levels [24]. This is particularly notable when the glomerular filtration rate drops below $20 \mathrm{~mL} / \mathrm{min}$ [24]. Additionally, based on the aforementioned studies, gender appears to be a confounding factor with the effects of BGP being differential between males and females. Vitamin K levels are obvious confounders. Moreover, menopausal status, adipose tissue, diabetic status are all expected to be confounders as well [25]. If we want studies that more accurately unravel the effect of BGP on the vasculature, we should standardize our BGP serum measurements and understand more carefully the confounders that should be accounted for. 


\section{Matrix Gla protein (MGP): beyond cardiovascular health}

Matrix Gla protein is a $14 \mathrm{kDa}$ vitamin K-dependent protein which after carboxylation can have up to 5 gamma-carboxyglutamic acid residues [26]. In addition to gamma-carboxylation, MGP requires post-translational serine phosphorylation. Phosphorylation occurs at 3 serine residues via the enzyme casein kinase [26, 27]. Phosphorylation regulates the protein secretion into the extracellular environment [26]. Based on the degree of carboxylation and phosphorylation, multiple forms of MGP can be found in the circulation and the extracellular matrix (Fig. 1). MGP is released from vascular smooth muscle cells and chondrocytes [28]. It was the first calcification inhibitor to be characterized [28]. The exact mechanism through which MGP inhibits VC is not completely understood. However, the carboxylated active form of MGP is believed (1) to bind to calcification crystals in blood vessels forming vesicles and apoptotic bodies, (2) to directly prevent calcium phosphate precipitation, and (3) to prevent the trans-differentiation of vascular smooth muscles cells into an osteogenic phenotype [26, 29].

The different forms of MGP can be used as a biomarker of vitamin $\mathrm{K}$ deficiency [30]. Vitamin $\mathrm{K}$ deficiency in CKD leads to a decrease in the levels of the phosphorylatedcarboxylated MGP (p-cMGP) and a rise in the levels of dephosphorylated undercarboxylated MGP (dp-ucMGP) [31]. Plasma dp-ucMGP levels increase as CKD advances with the highest levels found in CKD stage 5 [31]. Plasma dp-ucMGP is positively associated with VC and might be utilized as an early marker for vascular calcification in CKD patients [30,31].

Beyond the well-established effects of MGP in VC [32] studies also suggest that it has a role in skeletal health. Mice deficient in MGP develop diffuse VC as well as inappropriate calcification of the growth plate [28].

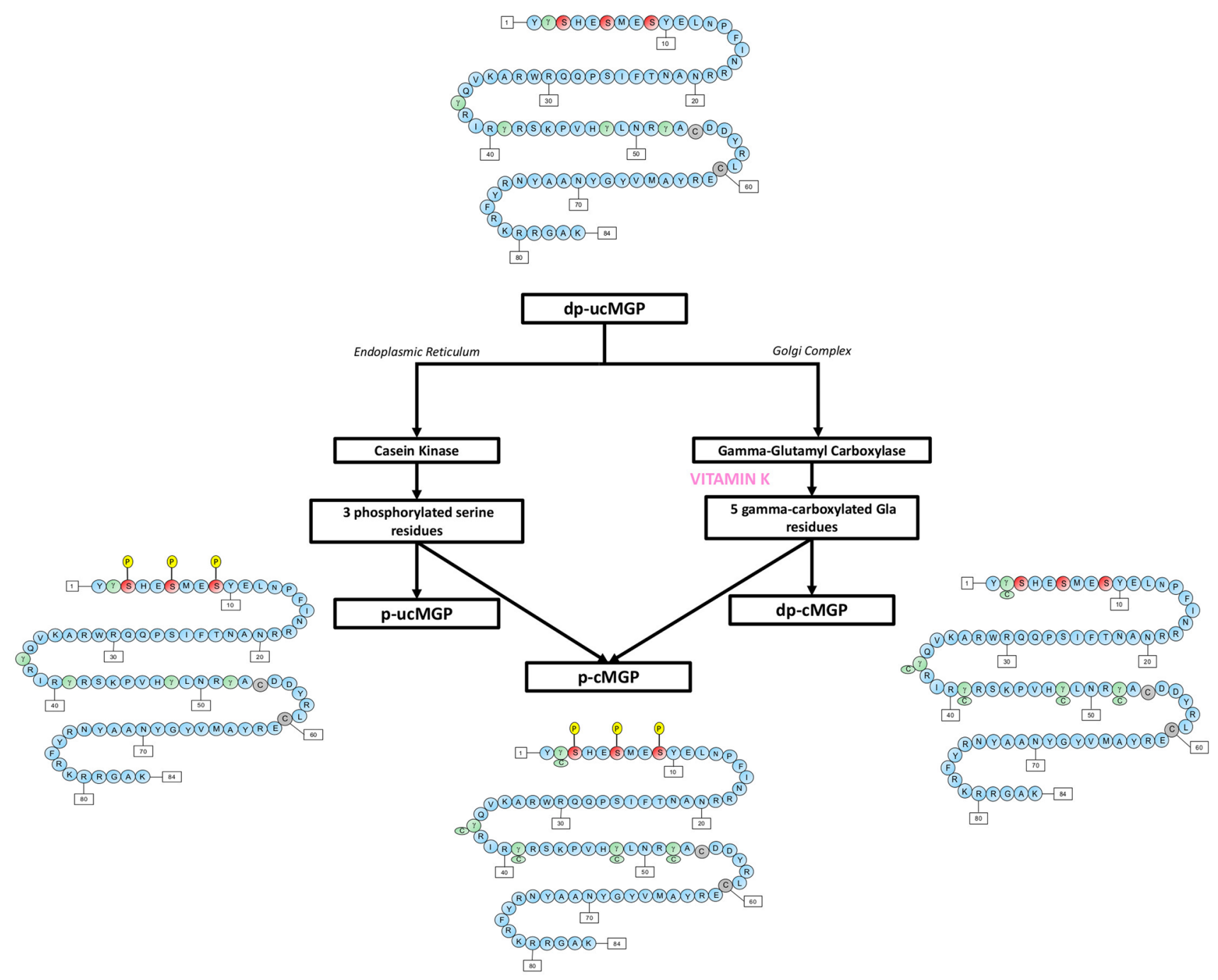

Fig. 1 Different forms of matrix Gla protein (MGP) 
Mice overexpressing $M g p$ in osteoblasts have a decrease in bone mineralization particularly in the tooth dentin and cementum. Thus, MGP affects bone mineralization [33]. MGP interacts with both osteoblasts and osteoclasts. Phosphate regulates MGP expression in osteoblast cultures via the ERK1/2-Fra-1 pathway [34]. Via Src/Rac1 signaling, MGP modulates osteoclastogenesis; MGP depletion favors while MGP excess inhibits osteoclast differentiation [35].

In clinical studies, homozygosity of the MGP rs1800802 minor allele, but not total serum MGP levels was associated with 0.56 times lower prevalence of hand osteoarthritis compared with having $\geq 1$ major allele at this locus (95\% CI 0.32-0.99, p < 0.05), suggesting a role for MGP in osteoarthritis [36]. Among 145 participants in the European Vertebral Osteoporosis Study, men with the homozygous MGP-7AA polymorphism had significantly more femoral bone loss as compared to those with genotypes -7GG and -7GA [37]. Those homozygous for MGP 83Ala-Ala had significantly more femoral neck loss as well as a greater tendency to vertebral fractures as compared to those with the genotypes $83 \mathrm{Thr}-\mathrm{Thr}$ and 83Thr-Ala. A decrease in BMD was observed only in MGP-7AA and MGP 83Ala-Ala genotypes. These associations were not found in the 151 women who participated in the study possibly because $94 \%$ of the women were post-menopausal and had independent post-menopausal bone loss that could have confounded the effect of the MGP polymorphisms.

The effect of MGP on fractures and bone density was similarly seen following kidney transplantation. Evenepoel et al. evaluated vitamin K deficiency as measured by dp-ucMGP levels in 468 de novo kidney transplant recipients. The patients with the highest tertile of dp-ucMGP levels had lower bone mineral density and had higher incident fractures independently of common fracture determinants (HR 2.21; 95\% CI 1.00-4.91; $p<0.05$ ) [38].

Studies evaluating the relationship between renal clearance and MGP levels are rare. In 842 outpatients with stable cardiovascular disease and a mean GFR of $76 \pm 23 \mathrm{~mL} / \mathrm{min}$, each $10 \mathrm{~mL} / \mathrm{min}$ lower GFR was associated with a $79 \mathrm{nM}$ lower ucMGP serum level $(\mathrm{p}<0.001)$, and a $0.1 \mathrm{mg} / \mathrm{L}$ higher cystatin-C was associated with a $39 \mathrm{nM}$ lower ucMGP serum levels $(\mathrm{p}<0.001)$ in multivariate adjusted models [39]. However, when Rennenberg et al. looked at this association, they found no significant correlations between total MGP levels in renal arterial and venous blood and renal clearance of 90 patients with hypertension [40]. It is important to note however that none of the patients in this cohort had a GFR $<26 \mathrm{~mL} /$ min [40]. A relationship between MGP levels and renal clearance at a GFR $<26 \mathrm{~mL} / \mathrm{min}$ is therefore still possible.
Vitamin $\mathrm{K}$ as ligand of nuclear receptors

Vitamin $\mathrm{K}$ can act as ligand of the nuclear steroid and xenobiotic receptor (SXR) and its murine ortholog, pregnane $\mathrm{X}$ receptor (PXR) [41]. SXR/PXR is present in different tissues, including osteoblastic cell lines [42, 43]. The presence of SXR/PXR in osteoblastic tissue is important as it could be the pathway through which vitamin $\mathrm{K}$ improves bone health [44].

Transcriptome analysis has revealed a number of bonerelated genes which are involved in the vitamin K-SXR pathway. These include tsukushi and matrilin-2, which are involved in collagen and extracellular matrix assembly $[45,46]$. In sarcoma cells, vitamin $\mathrm{K}$ up-regulates osteoblastic bone markers [43]. SXR/PXR knockout mice have increased bone resorption and decreased bone formation [47].

SXR is additionally involved in bone metabolism via its effect on vitamin D metabolism. In this role, SXR activation can have two effects. SXR activation by some drugs can lead to CYP3A4 expression (exerting 24- and 25-hydroxylase activity) and resultant vitamin D metabolism and deficiency. SXR activation can also lead to inhibition of CYP24A1 (24-hydroxylase activity) in the kidney therefore increasing 1,25(OH)D levels [48]. These data suggest that SXR/PXR is another pathway through which vitamin $\mathrm{K}$ is involved in bone homeostasis.

\section{Vitamin K in chronic kidney disease (CKD)}

The western diet does not provide enough vitamin $\mathrm{K}$ to activate VKDPs in all tissues [49]. This deficiency is more pronounced in adults over the age of 40 . Patients with CKD have even greater rates of vitamin $K$ deficiency as compared to the general population. The number of CKD patients who have vitamin K deficiency reaches 70-90\% of that population [50-52] (Table 1). Poor oral intake of vitamin $\mathrm{K}$ is the main cause of deficiency $[50,53]$. When compared to healthy individuals, the vitamin $\mathrm{K}$ intake of HD patients is particularly low on days of dialysis and the weekend [54]. The use of phosphorus binders in the dialysis population contributes to vitamin K deficiency as well [55]. Being lipophilic, vitamin K should not be removed via dialysis. However, studies to validate this hypothesis are needed, because serum levels of $25(\mathrm{OH})$-vitamin D, another lipophilic molecule, decreased in patients who were switched from conventional hemodialysis to online hemodiafiltration [56].

There are known implications of vitamin K deficiency in population-based studies and in kidney disease patients 
Table 1 Vitamin K and VKDP levels in kidney disease

\begin{tabular}{|c|c|c|c|c|c|c|}
\hline Author, year & $\begin{array}{l}\text { Number of } \\
\text { participants }\end{array}$ & Kidney disease stage & $\begin{array}{l}\text { Vitamin } \mathrm{K} \text { form } \\
\text { measured }\end{array}$ & $\begin{array}{l}\% \text { of patients with } \\
\text { vitamin K defi- } \\
\text { ciency }\end{array}$ & VKDP measured & $\begin{array}{l}\% \text { of patients } \\
\text { with measured } \\
\text { VKDP }\end{array}$ \\
\hline Kolheimer, 1997 [105] & 68 & ESKD-HD & Phylloquinone & 33 & & \\
\hline Pilkey, 2007 [106] & 142 & ESKD & Phylloquinone & 29 & ucBGP & 93 \\
\hline Holden, 2008 [52] & 21 & ESKD- PD & Phylloquinone & 24 & ucBGP & 60 \\
\hline Holden, 2010 [107] & 172 & CKD 3-5 & Phylloquinone & 6 & $\begin{array}{l}\text { ucBGP } \\
\text { PIVKAII }\end{array}$ & $\begin{array}{l}60 \\
97\end{array}$ \\
\hline Schurgers, 2010 [108] & 107 & CK2-5 and ESKD-HD & & & dp-ucMGP & 50 \\
\hline Schlieper, 2011 [109] & 188 & ESKD-HD & & & $\begin{array}{l}\text { PIVKA-II } \\
\text { dp-ucMGP }\end{array}$ & $\begin{array}{l}63 \\
100\end{array}$ \\
\hline Cranenburg, 2012 [54] & 40 & ESKD-HD & $\begin{array}{l}\text { Phylloquinone } \\
\text { Menaquinone }\end{array}$ & $\begin{array}{l}45 \\
100\end{array}$ & $\begin{array}{l}\text { PIVKAII } \\
\text { dp-ucMGP }\end{array}$ & $\begin{array}{l}82.5 \\
100\end{array}$ \\
\hline Westenfeld, 2012 [61] & 53 & ESKD-HD & Menaquinone & 100 & $\begin{array}{l}\text { PIVKAII } \\
\text { dp-ucMGP }\end{array}$ & $\begin{array}{l}92.5 \\
100\end{array}$ \\
\hline Fusaro, 2012 [57] & 387 & ESKD-HD & $\begin{array}{l}\text { Phylloquinone } \\
\text { Menaquinone-4 } \\
\text { Menaquinone-7 }\end{array}$ & $\begin{array}{l}23.5 \\
14.5 \\
35.4\end{array}$ & ucBGP & 100 \\
\hline Boxma, 2012 [110] & 60 & Post-Transplantation & & & dp-ucMGP & 80 \\
\hline Caluwe 2013 [62] & 165 & ESKD-HD & & & dp-ucMGP & 100 \\
\hline Delanaye, 2014 [111] & 160 & ESKD-HD & & & dp-ucMGP & 100 \\
\hline Keyzer, 2015 [63] & 518 & Post-Transplantation & & & dp-ucMGP & 91 \\
\hline Aoun, 2017 [112] & 50 & ESKD-HD & & & dp-ucMGP & 100 \\
\hline
\end{tabular}

$[57,58]$. In the Rotterdam study of 7983 men and women over the age of 55, intake of menaquinone protected against incident coronary heart disease (RR of highest tertile of menaquinone intake as compared to lowest tertile $=0.59, \mathrm{p}=0.007)$, and against coronary heart disease related mortality ( $R R$ of highest tertile of menaquinone intake as compared to lowest tertile $=0.43, \mathrm{p}=0.005)$. Additionally, the odds ratio of severe aortic calcification was significantly lower in the patients with the highest intake of menaquinone intake as compared to those with lowest intake (OR 0.48, p < 0.001) [59]. In the VIKI study, a cohort of 387 dialysis patients, $35.4 \%$ of patients had menaquinone- 7 deficiency, $23.5 \%$ of patients had vitamin K1 deficiency and $14.5 \%$ of patients had menquinone- 4 deficiency [57]. Patients with menaquinone-4 deficiency had significantly higher aortic calcification (10.6\% versus $1.3 \%, p=0.01)$. Menaquinone-7 deficiency was associated with significantly higher iliac calcifications (41\% versus $28.2 \%, p=0.009$ ) [57].

There is no gold-standard for the measurement of vitamin $\mathrm{K}$ levels and there is a lack in standardization. Instead, functional deficiency of vitamin $\mathrm{K}$ is used as a surrogate of vitamin $\mathrm{K}$ status in individuals. Vitamin $\mathrm{K}$ deficiency in $\mathrm{CKD}$ leads to a decrease in the levels of active MGP, a rise in the levels of dp-ucMGP, as well as a rise in the levels of ucBGP [37]. Plasma dp-ucMGP levels increase as CKD advances with highest levels being in CKD stage 5 [38]. A dp-ucMGP level of $>500 \mathrm{pmol} / \mathrm{L}$, ucBGP $>4.5 \mathrm{ng} / \mathrm{mL}$ [59] or protein induced by vitamin $\mathrm{K}$ absence-II (PIVKA-II) $>2 \mathrm{nM} / \mathrm{L}$ are indicative of vitamin $\mathrm{K}$ deficiency $[30,60]$.

In 53 dialysis patients, vitamin $\mathrm{K} 2$ supplementation resulted in a dose dependent decrease in functional vitamin $\mathrm{K}$ deficiency. After a 6-week supplementation regimen, dpucMGP levels were reduced $77 \%$ and $93 \%$ in the groups receiving daily oral administration of $135 \mu \mathrm{g}$ and $360 \mu \mathrm{g}$ of $\mathrm{K} 2$, respectively [61]. In $200 \mathrm{HD}$ patients receiving vitamin $\mathrm{K} 2$ at dose of 360,720 or $1080 \mu \mathrm{g}$ thrice weekly for 8 weeks, dp-uc-MGP levels decreased by $17 \%, 33 \%$ and $46 \%$ respectively [62]. Several studies show the same pattern (Table 2).

Although kidney transplantation is associated with an improvement in vitamin $\mathrm{K}$ levels [55], a deficiency in vitamin $\mathrm{K}$ was still found in up to $91 \%$ of kidney transplant patients. This deficiency may persist as long as 188 months post transplantation [38, 63]. Moreover, in at least one study, vitamin $\mathrm{K}$ deficiency in kidney transplant patients was associated with an almost 3 times increase in all-cause mortality [63].

\section{How current therapy of MBD in CKD influences vitamin $\mathrm{K}$ levels and VKDPs}

While MBD derangements contribute to renal osteodystrophy and to VC in CKD [64], treatments of MBD have not been sufficiently successful at reversing VC, improving cardiovascular events or decreasing mortality. We hypothesize that this might be partly explained by the negative impact of 
Table 2 Effect of Vitamin K supplementation on dephosphorylated-undercarboxylated MGP levels in ESKD

\begin{tabular}{|c|c|c|c|c|c|c|}
\hline Author, year & Study design & $\begin{array}{l}\text { Number of } \\
\text { participants }\end{array}$ & $\begin{array}{l}\text { Kidney } \\
\text { disease } \\
\text { stage }\end{array}$ & Intervention & Outcomes measured & Results \\
\hline Schlieper, 2011 [109] & Prospective & 17 & ESKD & $\begin{array}{l}\text { Vitamin } \mathrm{K} 2 \text { at } 135 \mu \mathrm{g} / \text { day } \\
\text { for } 6 \text { weeks }\end{array}$ & dp-ucMGP level & $\begin{array}{l}\text { Vitamin K2 supplementa- } \\
\text { tion resulted in a } 27 \% \\
\text { reduction in dp-ucMGP } \\
\text { levels. } \mathrm{p}=0.0027\end{array}$ \\
\hline Westenfeld, 2012 [61] & Prospective & 53 & ESKD & $\begin{array}{l}\text { Vitamin } \mathrm{K} 2 \text { at } 45,135 \text {, or } \\
360 \mu \mathrm{g} / \text { day for } 6 \text { weeks }\end{array}$ & dp-ucMGP level & $\begin{array}{l}\text { Vitamin K2 supplementa- } \\
\text { tion resulted in a dose- } \\
\text { dependent decrease in } \\
\text { the levels of dp-uc-MGP } \\
\text { by } 17.9 \%, 36.7 \% \text {, and } \\
61.1 \% \text { in the } 45-, 135-, \\
\text { and } 360-\mu \text { g groups, } \\
\text { respectively, compared } \\
\text { with baseline values. } \\
\text { p }<0.005\end{array}$ \\
\hline Caluwe, 2014 [62] & Prospective & 200 & ESKD & $\begin{array}{l}\text { Vitamin } \mathrm{K} 2 \text { at } 60,720 \text { or } \\
1080 \mu \mathrm{g} \text { thrice weekly for } \\
8 \text { weeks }\end{array}$ & dp-uc-MGP level & $\begin{array}{l}\text { Vitamin K2 resulted in a } \\
\text { dose-dependent decrease } \\
\text { in the levels of dp-uc- } \\
\text { MGP by } 17 \%, 33 \% \text { and } \\
46 \% \text { in the } 360-, 720- \\
\text { and } 1080-\mu \text { groups, } \\
\text { respectively, compared } \\
\text { to baseline values. } \\
\mathrm{p}<0.001\end{array}$ \\
\hline Aoun, 2017 [112] & Prospective & 50 & ESKD & $\begin{array}{l}360 \mu \mathrm{g} \text { of vitamin } \mathrm{K} 2 \\
\text { (menaquinone-7) for } \\
4 \text { weeks }\end{array}$ & dp-uc-MGP level & $\begin{array}{l}\text { Vitamin K2 reduced } \\
\text { dp-ucMGP by } 86 \% \text {. } \\
\text { p }<0.05\end{array}$ \\
\hline
\end{tabular}

some of the MBD treatments on vitamin $\mathrm{K}$ levels. One such treatment is sevelamer. Sevelamer is thought to bind fatsoluble vitamins $[65,66]$. Since vitamin $\mathrm{K}$ is a fat-soluble vitamin, Jansz et al. assessed the impact of sevelamer on vitamin $\mathrm{K}$ in patients who received a kidney transplantation. They found that sevelamer is associated with higher dpucMGP levels reflecting vitamin K deficiency [55]. This finding points to the possible need of giving vitamin K supplements to patients treated with sevelamer, but this approach should first be substantiated by a specific study.

However, some MBD treatments are associated with improvements in VKDPs. In an analysis of the VIKI study [57], the use of calcimimetics and vitamin D analogs was associated with higher levels of BGP. Calcimimetic use was also associated with higher levels of total MGP [19]. Therefore, this data suggests that calcimimetics and vitamin D analogs can help preserve or improve the activity of VKDPs.

\section{VKDPs beyond bone and vascular health}

\section{Growth arrest-specific protein 6 (Gas6)}

Gas6 is a gamma-carboxyglutamic acid (Gla) domaincontaining protein, member of the VKDPs family, which is present in several different tissues (e.g. vascular endothelium, kidney, heart, and the bone marrow). It is a ligand for the TAM (Tyro3-Axl-Mer) receptor family [67] and is thought to be involved in the stimulation of cell proliferation, migration and apoptosis [68, 69].

Gas6 and protein S are two homologous secreted proteins depending on vitamin $\mathrm{K}$ for a wide range of their biological functions. A discrete subset of these functions is mediated through their binding to and activation of the receptor tyrosine kinases Axl, Sky and Mer; in particular, the vitamin K-dependent protein Gas6 activates receptor tyrosine kinases of the Axl family [69].

A hallmark of the Gas6-Axl system is the unique ability of both Gas6 and protein S to tether their non receptor-binding regions to the negatively charged membranes of apoptotic cells. A relevant amount of evidence suggests that the Gas6-Axl system is able to regulate cell survival, proliferation, migration, adhesion and phagocytosis. Consequently, an altered expression, or a compromised activity of its components have been detected in a variety of diseases, including different cancer types. Moreover, Axl overactivation can equally occur without ligand binding, which has implications for tumorigenesis. [70].

Upregulation of Gas6 has been described in different malignancies [71], and an increased expression of either 
Gas6 or TAM receptor proved to be predictive of poor prognosis [72]. A number of animal studies highlighted the role of Gas6 in the processes of carcinogenesis [71-73], while clinical studies are rarer, but ultimately show consistent findings. Ovarian cancer samples from 90 patients had significantly higher expression of Gas6 and Axl as compared to normal ovarian tissue [73], RNA PCR from 42 glioblastoma frozen sections demonstrated that Gas6 and Axl are overexpressed both in the tumoral, as well as in the surrounding vascular, tissue [74]. Furthermore, glioblastoma patients whose tumors expressed higher Gas6 and Axl levels had significantly higher risk of tumor relapse as well as shorter time to relapse [74]. A similar observation has been reported in osteosarcoma; indeed, in 62 osteosarcoma patients, Axl was highly expressed in $43.5 \%$ of the cases, characterized by a significantly higher rate of recurrence, lung metastases, as well as a lower survival [75]. Gas6-Axl is also important as mechanisms of resistance to anticancer therapy; indeed, resistance to tyrosine kinase inhibitors in non-small cell cancer and renal cell carcinoma (RCC) was found to be driven by Axl [76].

As far as RCC, the Axl protein proved to be highly expressed in clear cell RCC cells deficient in functional von Hippel-Lindau (VHL) protein, a tumor suppressor gene often inactivated in ccRCC. VHL reconstituted cells expressed decreased levels of Axl protein, but not Axl mRNA, suggesting that VHL may regulate Axl expression. Furthermore, Gas6-mediated activation of Axl in ccRCC cells resulted in Axl phosphorylation, receptor down-regulation, decreased cell-viability, as well as migratory capacity, whilst no effects of the Gas6/Axl system could be detected on invasion. Moreover, in ccRCC tumor tissues, Axl was phosphorylated and Gas6 gamma-carboxylated, suggesting these molecules to be active in vivo. [77].

All the above has practical therapeutic implications, as targeting the Gas6-Axl pathway through the multikinase inhibitor cabozantinib proved to be an active treatment option for metastatic RCC patients progressing on standard antiangiogenic therapy [78].

\section{Periostin}

Periostin is another member of the VKDP family. Similar to other VKDPs, the carboxylation of periostin is dependent on vitamin $\mathrm{K}$. However, it is unknown how the carboxylation status of periostin influences its functions in different tissues. Periostin is an extracellular matrix protein that binds integrins playing a role in cellular adhesion and migration [79]. It plays a role in collagen assembly in several tissues and is upregulated when tissues are subjected to stress [79-81]. Following cardiac injury, periostin is expressed in cardiac myofibroblasts and vascular smooth muscle cells contributing to a profibrotic phenotype [81-83]. Similar to other VKDPs, periostin has also been found in many cancers [84-86]. Periostin induces tumor angiogenesis [84, 85] and lymphangiogenesis [85], and its association with cancer confers a worse prognosis to patients [85]. The role of periostin in breast cancer has been described. Periostin is expressed in invasive ductal carcinoma cells [87]. Its expression increases with the cancer grade, suggesting that periostin may play a role in cancer progression [88]. Periostin can also serve as marker of breast cancer metastasis. Human breast cancer exosomes contain periostin. Further, periostin enriched exosomes were found in patients with lymph node metastasis as compared to those with localized disease [89]. Finally, periostin may have a role in breast cancer prognostication. In 259 breast cancer patients who underwent surgical and radiation therapy, local recurrence-free survival, distant metastasis-free survival and overall survival were significantly lower in the patients whose tumors expressed periostin as compared to those whose tumors were negative for periostin [90].

\section{Gla-rich protein (GRP)}

Gla-rich protein is one of the newest members of the VKDP family. Its name derives from the large amount of Gla residues, which comprise $22 \%$ of its composition [91], and which make it the VKDP with the highest concentration of Gla residues. Since its discovery, GRP has been found to have a role as an anti-inflammatory protein [92]. In vivo, it prevents osteoarthritis progression [93]. It additionally plays a role in mineralization. In both animal models and in humans, GRP has been found to colocalize with mineral deposits at sites of calcification [94]. Further work demonstrates that similar to MGP, GRP in its carboxylated but not in its undercarboxylated form is a calcification inhibitor [95]. Although GRP role in cancer is less established as compared to other VKDPs, there is growing interest surrounding this protein. The undercarboxylated form as compared to the carboxylated form of GRP is found in more abundance in skin and breast cancer cells, particularly in microcalcifications associated with these tumors [96]. Therefore, GRP may be involved in cancer-related calcifications and as such may prove to be a therapeutic target for some types of cancer.

\section{Vitamin $\mathrm{K}$ in cancer}

Several VKDPs are involved in tumorigenesis [71, 84, 85] (Table 3). Vitamin K2 administration in vivo inhibits the cellular proliferation of several cancers $[96,97]$. This led to a number of studies investigating the role of vitamin $\mathrm{K}$ intake and supplementation in preventing cancer development, progression and recurrence. In the European Prospective Investigation into Cancer and Nutrition-Heidelberg cohort study 
Table 3 Effects of VKDPs on cancer development and progression

Vitamin $\mathrm{K}$ dependent proteins activity may modulate cancer behav-

ior

Gas 6

Angiogenesis

Tumor progression

Higher tumor recurrence

Metastasis and poorer prognosis

Cancer therapy resistance

Angiogenesis

Lymphangiogenesis

Tumor progression

Poorer prognosis

Tumor progression
$\mathrm{K}$ supplementation strategies in order to further understand their effect on clinical outcomes.

\section{Compliance with ethical standards}

Conflict of interest The authors declare that they have no conflict of interest.

Ethical approval Not applicable. which included 24,340 cancer-free participants followed up for 10 years, there was a significant inverse association between vitamin $\mathrm{K} 2$ intake and cancer mortality, but not cancer incidence [98]. Similarly, in the Prevención con Dieta Mediterránea study, which enrolled 7216 participants followed up for a median of 4.8 years, subjects who increased their dietary intake of both vitamin $\mathrm{K} 1$ and $\mathrm{K} 2$ had decreased cancer incidence [99].

The undercarboxylated form of prothrombin (PIVKAII), a VKDP, is upregulated in hepatocellular carcinoma (HCC) [100]. Vitamin K2 supplementation in patients who underwent curative hepatectomy or radiofrequency ablation for HCC suppressed HCC recurrence, though this effect did not reach statistical significance in any of these studies [101, 102]. In contrast, $45 \mathrm{mg}$ per day of vitamin $\mathrm{K} 2$ supplementation resulted in significantly lower risk of HCC development in 21 women who had viral cirrhosis as compared to 19 women with viral cirrhosis who did not receive supplementation [103]. This suggests that vitamin K2 may play a role in preventing the development of HCC in high risk patients. Overall, the association and the relationship of vitamin $\mathrm{K}$ with cancer is still uncertain and under investigation. Further studies are needed to define this role of vitamin $\mathrm{K}$.

\section{Conclusion}

Substantial research has made it clear that VKDPs or Vitamin-K related pathways can be used in the future to diagnose, treat and prognosticate a number of health conditions. There are still more vitamin K-related roles to be uncovered and which will further our understanding of the physiological and pathological importance of vitamin K status. It will also prove important to recognize the differential actions of vitamin K1 and vitamin K2, and to develop standardized techniques that can directly measure vitamin $\mathrm{K}$ levels instead of our current reliance on functional vitamin $\mathrm{K}$ status as measured by VKDPs levels [104]. This will allow to develop trials that can evaluate selective and optimal vitamin

\section{References}

1. Shearer MJ (1995) Vitamin K. Lancet 345(8944):229-234

2. Azuma K et al (2015) Osteoblast-specific gamma-glutamyl carboxylase-deficient mice display enhanced bone formation with aberrant mineralization. J Bone Miner Res 30(7):1245-1254

3. Fusaro $\mathrm{M}$ et al (2011) Vitamin $\mathrm{K}$, bone fractures, and vascular calcifications in chronic kidney disease: an important but poorly studied relationship. J Endocrinol Invest 34(4):317-323

4. Silaghi CN et al (2019) Vitamin $\mathrm{K}$ dependent proteins in kidney disease. Int J Mol Sci 20(7)

5. Fusaro $\mathrm{M}$ et al (2017) Vitamin $\mathrm{K}$ and bone. Clin Cases Miner Bone Metab 14(2):200-206

6. Morris DP et al (1995) Processive post-translational modification. Vitamin K-dependent carboxylation of a peptide substrate. J Biol Chem 270(51):30491-30498

7. Van de Loo PG et al (1987) The effect of Gla-containing proteins on the precipitation of insoluble salts. Biochem Biophys Res Commun 142(1):113-119

8. Boskey AL et al (1998) Fourier transform infrared microspectroscopic analysis of bones of osteocalcin-deficient mice provides insight into the function of osteocalcin. Bone 23(3):187-196

9. Ritter NM, Farach-Carson MC, Butler WT (1992) Evidence for the formation of a complex between osteopontin and osteocalcin. J Bone Miner Res 7(8):877-885

10. Wei J et al (2014) Bone-specific insulin resistance disrupts whole-body glucose homeostasis via decreased osteocalcin activation. J Clin Invest 124(4):1-13

11. Lee NK et al (2007) Endocrine regulation of energy metabolism by the skeleton. Cell 130(3):456-469

12. Wei J et al (2014) Osteocalcin promotes beta-cell proliferation during development and adulthood through Gprc6a. Diabetes 63(3):1021-1031

13. Oury F et al (2013) Osteocalcin regulates murine and human fertility through a pancreas-bone-testis axis. J Clin Invest 123(6):2421-2433

14. Luo XH et al (2009) Development of arterial calcification in adiponectin-deficient mice: adiponectin regulates arterial calcification. J Bone Miner Res 24(8):1461-1468

15. Dou J et al (2014) Osteocalcin attenuates high fat diet-induced impairment of endothelium-dependent relaxation through Akt/ eNOS-dependent pathway. Cardiovasc Diabetol 13:74

16. Huang L et al (2017) Osteocalcin improves metabolic profiles, body composition and arterial stiffening in an induced diabetic rat model. Exp Clin Endocrinol Diabetes 125(4):234-240

17. Bacchetta J et al (2009) The relationship between adipokines, osteocalcin and bone quality in chronic kidney disease. Nephrol Dial Transplant 24(10):3120-3125

18. Levy RJ, Gundberg C, Scheinman R (1983) The identification of the vitamin K-dependent bone protein osteocalcin as one of the gamma-carboxyglutamic acid containing proteins present in 
calcified atherosclerotic plaque and mineralized heart valves. Atherosclerosis 46(1):49-56

19. Fleet JC, Hock JM (1994) Identification of osteocalcin mRNA in nonosteoid tissue of rats and humans by reverse transcriptionpolymerase chain reaction. J Bone Miner Res 9(10):1565-1573

20. Fusaro $\mathrm{M}$ et al (2016) Calcimimetic and vitamin D analog use in hemodialyzed patients is associated with increased levels of vitamin K dependent proteins. Endocrine 51(2):333-341

21. Parker BD et al (2010) Association of osteocalcin and abdominal aortic calcification in older women: the study of osteoporotic fractures. Calcif Tissue Int 86(3):185-191

22. Millar SA et al (2017) Osteocalcin, vascular calcification, and atherosclerosis: a systematic review and meta-analysis. Front Endocrinol (Lausanne) 8:183

23. Gundberg CM et al (1985) Osteocalcin in human serum: a circadian rhythm. J Clin Endocrinol Metab 60(4):736-739

24. Delmas PD et al (1983) Effect of renal function on plasma levels of bone Gla-protein. J Clin Endocrinol Metab 57(5):1028-1030

25. Li J et al (2016) An overview of osteocalcin progress. J Bone Miner Metab 34(4):367-379

26. Gallieni M, Fusaro M (2014) Vitamin K and cardiovascular calcification in CKD: is patient supplementation on the horizon? Kidney Int 86(2):232-234

27. Schurgers LJ, Cranenburg EC, Vermeer C (2008) Matrix Glaprotein: the calcification inhibitor in need of vitamin $\mathrm{K}$. Thromb Haemost 100(4):593-603

28. Luo G et al (1997) Spontaneous calcification of arteries and cartilage in mice lacking matrix GLA protein. Nature 386(6620):78-81

29. Speer MY et al (2009) Smooth muscle cells give rise to osteochondrogenic precursors and chondrocytes in calcifying arteries. Circ Res 104(6):733-741

30. Cranenburg EC et al (2010) Characterisation and potential diagnostic value of circulating matrix Gla protein (MGP) species. Thromb Haemost 104(4):811-822

31. Thamratnopkoon S et al (2017) Correlations of plasma desphosphorylated uncarboxylated matrix Gla protein with vascular calcification and vascular stiffness in chronic kidney disease. Nephron 135(3):167-172

32. Munroe PB et al (1999) Mutations in the gene encoding the human matrix Gla protein cause Keutel syndrome. Nat Genet 21(1):142-144

33. Kaipatur NR, Murshed M, McKee MD (2008) Matrix Gla protein inhibition of tooth mineralization. J Dent Res 87(9):839-844

34. Julien M et al (2009) Phosphate-dependent regulation of MGP in osteoblasts: role of ERK1/2 and Fra-1. J Bone Miner Res 24(11):1856-1868

35. Zhang $Y$ et al (2019) Unexpected role of matrix Gla protein in osteoclasts: inhibiting osteoclast differentiation and bone resorption. Mol Cell Biol 39(12)

36. Misra D et al (2011) Matrix Gla protein polymorphism, but not concentrations, is associated with radiographic hand osteoarthritis. J Rheumatol 38(9):1960-1965

37. Tunon-Le Poultel D et al (2014) Association of matrix Gla protein gene functional polymorphisms with loss of bone mineral density and progression of aortic calcification. Osteoporos Int 25(4):1237-1246

38. Evenepoel P et al (2019) Poor vitamin K status is associated with low bone mineral density and increased fracture risk in end-stage renal disease. J Bone Miner Res 34(2):262-269

39. Parker BD et al (2009) Association of kidney function and uncarboxylated matrix Gla protein: data from the Heart and Soul Study. Nephrol Dial Transplant 24(7):2095-2101

40. Rennenberg RJ et al (2008) Renal handling of matrix Gla-protein in humans with moderate to severe hypertension. Hypertens Res 31(9):1745-1751
41. Azuma K, Ouchi Y, Inoue S (2014) Vitamin K: novel molecular mechanisms of action and its roles in osteoporosis. Geriatr Gerontol Int 14(1):1-7

42. Albermann $\mathrm{N}$ et al (2005) Expression of the drug transporters MDR1/ABCB1, MRP1/ABCC1, MRP2/ABCC2, BCRP/ ABCG2, and PXR in peripheral blood mononuclear cells and their relationship with the expression in intestine and liver. Biochem Pharmacol 70(6):949-958

43. Tabb MM et al (2003) Vitamin K2 regulation of bone homeostasis is mediated by the steroid and xenobiotic receptor SXR. J Biol Chem 278(45):43919-43927

44. Cockayne $\mathrm{S}$ et al (2006) Vitamin K and the prevention of fractures: systematic review and meta-analysis of randomized controlled trials. Arch Intern Med 166(12):1256-1261

45. Klatt AR et al (2011) The matrilins: modulators of extracellular matrix assembly. Int J Biochem Cell Biol 43(3):320-330

46. Ichikawa $T$ et al (2006) Steroid and xenobiotic receptor SXR mediates vitamin $\mathrm{K} 2$-activated transcription of extracellular matrix-related genes and collagen accumulation in osteoblastic cells. J Biol Chem 281(25):16927-16934

47. Azuma K et al (2010) Pregnane X receptor knockout mice display osteopenia with reduced bone formation and enhanced bone resorption. J Endocrinol 207(3):257-263

48. Zhou $C$ et al (2006) Steroid and xenobiotic receptor and vitamin D receptor crosstalk mediates CYP24 expression and drug-induced osteomalacia. J Clin Invest 116(6):1703-1712

49. Theuwissen E et al (2014) Vitamin K status in healthy volunteers. Food Funct 5(2):229-234

50. Fusaro $\mathrm{M}$ et al (2017) Low vitamin K1 intake in haemodialysis patients. Clin Nutr 36(2):601-607

51. Vervloet MG (2017) Brandenburg VM2; CKD-MBD working group of ERA-EDTA. Circulating markers of bone turnover. J Nephrol 30(5):663-670. https://doi.org/10.1007/s40620-0170408-8 (epub 2017 May 13)

52. Holden RM et al (2008) Vitamin K status of Canadian peritoneal dialysis patients. Perit Dial Int 28(4):415-418

53. Wyskida K et al (2015) Daily intake and serum concentration of menaquinone-4 (MK-4) in haemodialysis patients with chronic kidney disease. Clin Biochem 48(18):1246-1251

54. Cranenburg EC et al (2012) Vitamin K intake and status are low in hemodialysis patients. Kidney Int 82(5):605-610

55. Jansz TT et al (2018) The role of kidney transplantation and phosphate binder use in vitamin $\mathrm{K}$ status. PLoS One 13(8):e0203157

56. Uhlin F et al (2019) Long-term follow-up of biomarkers of vascular calcification after switch from traditional hemodialysis to online hemodiafiltration. Scand J Clin Lab Invest 79(3):174-181

57. Fusaro $\mathrm{M}$ et al (2012) Vitamin K, vertebral fractures, vascular calcifications, and mortality: vitamin K Italian (VIKI) dialysis study. J Bone Miner Res 27(11):2271-2278

58. Geleijnse JM et al (2004) Dietary intake of menaquinone is associated with a reduced risk of coronary heart disease: the Rotterdam Study. J Nutr 134(11):3100-3105

59. Kuwabara A et al (2009) High prevalence of vitamin K and D deficiency and decreased BMD in inflammatory bowel disease. Osteoporos Int 20(6):935-942

60. Riphagen IJ et al (2016) Measurement of plasma vitamin $\mathrm{K} 1$ (phylloquinone) and K2 (menaquinones-4 and -7) using HPLC-tandem mass spectrometry. Clin Chem Lab Med 54(7):1201-1210

61. Westenfeld R et al (2012) Effect of vitamin K2 supplementation on functional vitamin $\mathrm{K}$ deficiency in hemodialysis patients: a randomized trial. Am J Kidney Dis 59(2):186-195

62. Caluwe R et al (2014) Vitamin K2 supplementation in haemodialysis patients: a randomized dose-finding study. Nephrol Dial Transplant 29(7):1385-1390 
63. Keyzer CA et al (2015) Vitamin K status and mortality after kidney transplantation: a cohort study. Am J Kidney Dis 65(3):474-483

64. Block GA et al (2004) Mineral metabolism, mortality, and morbidity in maintenance hemodialysis. J Am Soc Nephrol 15(8):2208-2218

65. Susantitaphong P, Jaber BL (2012) Potential interaction between sevelamer and fat-soluble vitamins: a hypothesis. Am J Kidney Dis 59(2): 165-167

66. Takagi K et al (2010) Metal ion and vitamin adsorption profiles of phosphate binder ion-exchange resins. Clin Nephrol 73(1):30-35

67. Stitt TN et al (1995) The anticoagulation factor protein $\mathrm{S}$ and its relative, Gas6, are ligands for the Tyro 3/Axl family of receptor tyrosine kinases. Cell 80(4):661-670

68. Manfioletti $\mathrm{G}$ et al (1993) The protein encoded by a growth arrestspecific gene (gas6) is a new member of the vitamin K-dependent proteins related to protein $\mathrm{S}$, a negative coregulator in the blood coagulation cascade. Mol Cell Biol 13(8):4976-4985

69. Sasaki T et al (2006) Structural basis for Gas6-Axl signalling. EMBO J 25(1):80-87

70. Hafizi S, Dahlbäck B (2006) Gas6 and protein S. Vitamin $\mathrm{K}$-dependent ligands for the Axl receptor tyrosine kinase subfamily. FEBS J 273(23):5231-5244 (epub 2006 Oct 25)

71. Chiu KC et al (2015) Polarization of tumor-associated macrophages and Gas6/Axl signaling in oral squamous cell carcinoma. Oral Oncol 51(7):683-689

72. Wu G et al (2017) Molecular insights of Gas6/TAM in cancer development and therapy. Cell Death Dis 8(3):e2700

73. Sun W, Fujimoto J, Tamaya T (2004) Coexpression of Gas6/Axl in human ovarian cancers. Oncology 66(6):450-457

74. Hutterer M et al (2008) Axl and growth arrest-specific gene 6 are frequently overexpressed in human gliomas and predict poor prognosis in patients with glioblastoma multiforme. Clin Cancer Res 14(1):130-138

75. Han J et al (2013) Gas6/Axl mediates tumor cell apoptosis, migration and invasion and predicts the clinical outcome of osteosarcoma patients. Biochem Biophys Res Commun 435(3):493-500

76. Zhang $\mathrm{Z}$ et al (2012) Activation of the AXL kinase causes resistance to EGFR-targeted therapy in lung cancer. Nat Genet 44(8):852-860

77. Gustafsson A, Boström AK, Ljungberg B, Axelson H, Dahlbäck B (2009) Gas6 and the receptor tyrosine kinase Axl in clear cell renal cell carcinoma. PLoS One 4(10):e7575. https://doi. org/10.1371/journal.pone.0007575

78. Zhou L, Liu XD, Sun M, Zhang X, German P, Bai S, Ding Z, Tannir N, Wood CG, Matin SF, Karam JA, Tamboli P, Sircar K, Rao P, Rankin EB, Laird DA, Hoang AG, Walker CL, Giaccia AJ, Jonasch E (2016) Targeting MET and AXL overcomes resistance to sunitinib therapy in renal cell carcinoma. Oncogene 35(21):2687-2697. https://doi.org/10.1038/onc.2015.343 (epub 2015 Sep 14)

79. Norris RA et al (2007) Periostin regulates collagen fibrillogenesis and the biomechanical properties of connective tissues. J Cell Biochem 101(3):695-711

80. Egbert $\mathrm{M}$ et al (2014) The matricellular protein periostin contributes to proper collagen function and is downregulated during skin aging. J Dermatol Sci 73(1):40-48

81. Conway SJ, Molkentin JD (2008) Periostin as a heterofunctional regulator of cardiac development and disease. Curr Genomics 9(8):548-555

82. Dixon IMC, Landry NM, Rattan SG (2019) Periostin reexpression in heart disease contributes to cardiac interstitial remodeling by supporting the cardiac myofibroblast phenotype. Adv Exp Med Biol 1132:35-41
83. Oka T et al (2007) Genetic manipulation of periostin expression reveals a role in cardiac hypertrophy and ventricular remodeling. Circ Res 101(3):313-321

84. Shao R et al (2004) Acquired expression of periostin by human breast cancers promotes tumor angiogenesis through up-regulation of vascular endothelial growth factor receptor 2 expression. Mol Cell Biol 24(9):3992-4003

85. Takanami I, Abiko T, Koizumi S (2008) Expression of periostin in patients with non-small cell lung cancer: correlation with angiogenesis and lymphangiogenesis. Int J Biol Mark 23(3):182-186

86. Cui D et al (2017) The multifaceted role of periostin in priming the tumor microenvironments for tumor progression. Cell Mol Life Sci 74(23):4287-4291

87. Ratajczak-Wielgomas K et al (2016) Periostin expression in cancer-associated fibroblasts of invasive ductal breast carcinoma. Oncol Rep 36(5):2745-2754

88. Ratajczak-Wielgomas K et al (2017) Expression of periostin in breast cancer cells. Int J Oncol 51(4):1300-1310

89. Vardaki I et al (2016) Periostin is identified as a putative metastatic marker in breast cancer-derived exosomes. Oncotarget 7(46):74966-74978

90. Li C et al (2018) Prognostic value of periostin in early-stage breast cancer treated with conserving surgery and radiotherapy. Oncol Lett 15(5):8072-8078

91. Viegas CS et al (2008) Gla-rich protein (GRP), a new vitamin K-dependent protein identified from sturgeon cartilage and highly conserved in vertebrates. J Biol Chem 283(52):36655-36664

92. Viegas CSB et al (2017) Gla-rich protein function as antiinflammatory agent in monocytes/macrophages: implications for calcification-related chronic inflammatory diseases. PLoS One 12(5):e0177829

93. Cavaco S et al (2016) Gla-rich protein is involved in the crosstalk between calcification and inflammation in osteoarthritis. Cell Mol Life Sci 73(5):1051-1065

94. Viegas CS et al (2009) Gla-rich protein is a novel vitamin $\mathrm{K}$-dependent protein present in serum that accumulates at sites of pathological calcifications. Am J Pathol 175(6):2288-2298

95. Viegas CS et al (2015) Gla-rich protein acts as a calcification inhibitor in the human cardiovascular system. Arterioscler Thromb Vasc Biol 35(2):399-408

96. Kiely M et al (2015) Real-time cell analysis of the inhibitory effect of vitamin $\mathrm{K} 2$ on adhesion and proliferation of breast cancer cells. Nutr Res 35(8):736-743

97. Refolo MG et al (2017) IGF-1R tyrosine kinase inhibitors and Vitamin K1 enhance the antitumor effects of Regorafenib in HCC cell lines. Oncotarget 8(61):103465-103476

98. Nimptsch K et al (2010) Dietary vitamin K intake in relation to cancer incidence and mortality: results from the Heidelberg cohort of the European Prospective Investigation into Cancer and Nutrition (EPIC-Heidelberg). Am J Clin Nutr 91(5):1348-1358

99. Juanola-Falgarona $\mathrm{M}$ et al (2014) Dietary intake of vitamin $\mathrm{K}$ is inversely associated with mortality risk. J Nutr 144(5):743-750

100. Nakao A et al (1991) Abnormal prothrombin (DES-gammacarboxy prothrombin) in hepatocellular carcinoma. Hepatogastroenterology 38(5):450-453

101. Ishizuka $\mathrm{M}$ et al (2012) Effect of menatetrenone, a vitamin $\mathrm{k} 2$ analog, on recurrence of hepatocellular carcinoma after surgical resection: a prospective randomized controlled trial. Anticancer Res 32(12):5415-5420

102. Riaz IB et al (2012) Role of vitamin K2 in preventing the recurrence of hepatocellular carcinoma after curative treatment: a meta-analysis of randomized controlled trials. BMC Gastroenterol 12:170

103. Habu D et al (2004) Role of vitamin K2 in the development of hepatocellular carcinoma in women with viral cirrhosis of the liver. JAMA 292(3):358-361 
104. Fusaro $\mathrm{M}$ et al (2017) Vitamin K plasma levels determination in human health. Clin Chem Lab Med 55(6):789-799

105. Kohlmeier M et al (1997) Bone health of adult hemodialysis patients is related to vitamin $\mathrm{K}$ status. Kidney Int 51(4):1218-1221

106. Pilkey RM et al (2007) Subclinical vitamin K deficiency in hemodialysis patients. Am J Kidney Dis 49(3):432-439

107. Holden RM et al (2010) Vitamins K and D status in stages 3-5 chronic kidney disease. Clin J Am Soc Nephrol 5(4):590-597

108. Schurgers LJ et al (2010) The circulating inactive form of matrix gla protein is a surrogate marker for vascular calcification in chronic kidney disease: a preliminary report. Clin J Am Soc Nephrol 5(4):568-575

109. Schlieper $\mathrm{G}$ et al (2011) Circulating nonphosphorylated carboxylated matrix gla protein predicts survival in ESRD. J Am Soc Nephrol 22(2):387-395

110. Boxma PY et al (2012) Vitamin k intake and plasma desphosphouncarboxylated matrix Gla-protein levels in kidney transplant recipients. PLoS One 7(10):e47991
111. Delanaye P et al (2014) Dephosphorylated-uncarboxylated Matrix Gla protein concentration is predictive of vitamin K status and is correlated with vascular calcification in a cohort of hemodialysis patients. BMC Nephrol 15:145

112. Aoun $\mathrm{M}$ et al (2017) High dephosphorylated-uncarboxylated MGP in hemodialysis patients: risk factors and response to vitamin K2, a pre-post intervention clinical trial. BMC Nephrol 18(1):191

Publisher's Note Springer Nature remains neutral with regard to jurisdictional claims in published maps and institutional affiliations. 